\title{
ANÁLISE EXPERIMENTAL EM UM CILINDRO DE VARETAS DE UMA COLHEDORA DE CAFÉ PARA DIAGNÓSTICO DE FALHA ${ }^{1}$
}

\author{
Carlos Ademir da Silva ${ }^{2}$ \\ Alexandre Assis Rezende Campos \\ Ricardo Rodrigues Magalhães \\ Ednilton Tavares de Andrade \\ Carlos Eduardo Silva Volpato \\ Leomar Santos Marques
}

\begin{abstract}
RESUMO
Colhedoras de café trabalham com um sistema de vibração para promover a derriça dos grãos. O sistema de vibração geralmente é acoplado na extremidade de um eixo, denominado por cilindro vibrador de varetas. Este cilindro pode apresentar falhas em campo, as quais geralmente ocorrem por fratura na região da solda entre o cilindro e seu flange. Observa-se em campo que, este tipo de falha ocorre em um curto intervalo de tempo, antes de 12 meses de trabalho constante, o que requer diagnóstico de falhas. Este trabalho tem como objetivo principal realizar o diagnóstico de falha em um cilindro vibrador de varetas de uma colhedora de café. Para isso, foi realizado o mapeamento da fratura e foram confeccionados corpos de prova para a realização de ensaios mecânicos destrutivos e não destrutivos (ensaio de tração, análise química dos materiais do cilindro vibrador de varetas e flange, metalografia das juntas soldadas e ensaios de dureza Vickers e Brinell. Os resultados das análises químicas e de dureza Brinell comprovaram que o material do cilindro de varetas se trata de um aço de baixo teor de carbono. Os resultados de dureza Vickers evidenciaram a não homogeneidade do metal depositado. Os resultados obtidos nos ensaios de tração foram próximos a valores encontrados na literatura, exceto para o alongamento. Os resultados metalográficos da junta soldada evidenciaram defeitos, como trinca e porosidade, que podem influenciara fratura. Neste sentido, foi proposto um procedimento de soldagem (EPs) para a melhoria do processo de fabricação da peça analisada.
\end{abstract}

Palavras-chave: Colhedora de café. Ensaio mecânicos. Diagnóstico de falhas.

\section{EXPERIMENTAL ANALYSIS IN A STELL CYLINDER OF A COFFEE HARVEST FOR FAILURE DIAGNOSIS}

\begin{abstract}
Coffee harvesters work with vibration system in order to promote the breaking of the grains peduncle. The vibration system is usually coupled to the end of an axis, called a rod vibrating cylinder. This cylinder can present failures on duty, which usually occurs due to fracture failure

${ }^{1}$ Como citar este artigo:

SILVA, C. A. da et al. Análise experimental em um cilindro de varetas de uma colhedora de café para diagnóstico de falha. ForScience, Formiga, v. 8, n. 2, e00632, jul./dez. 2020. DOI: 10.29069/forscience.2020v8n2.e632.

${ }^{2}$ Autor para correspondência: Carlos Ademir da Silva, e-mail: carlosademir2016@yahoo.com.br
\end{abstract}


in the weld region between the cylinder and its flange. It is observed that this type of failure occurs in a short time, before 12 months of constant work, which requires a failure diagnosis. The main objective of this work is to perform failure diagnosis in the vibrating rod cylinder of a coffee harvester. To this end, a the fracture mapping was performed and samples were made specimens for destructive and non-destructive mechanical tests, such as tensile testing, chemical analysis of the pipe and flange materials, metallography of the welded joints and hardness testing Vickens and Brinell. Through these tests, it was observed problems due to the welding process applied between the rod cylinder and the flange, and to manufacturing defects of the axle (arising from the casting process). As a result, it was observed a probable fatigue failure process leading to a short service life in the cylinder-flange assembly. To solve this problem, a welding procedure (EPs) is proposed to improve the fabrication process of the rod cylinder.

Keywords: Coffee harvester. Mechanical tests. Failure diagnosis.

\section{INTRODUÇÃO}

A mecanização agrícola em grande escala aconteceu com a utilização de máquinas colhedoras após a segunda guerra mundial. A partir do desenvolvimento tecnológico ocorrido nesse período, foi possível desenvolver tratores e colhedoras de grande porte. Antes disso, a colheita do café era realizada manualmente ou de forma semi-mecanizada. Atualmente, o mercado de máquinas agrícolas conta com modernas derriçadoras de café, podendo ser autopropelidas ou tracionadas por tratores. Independentemente do tipo, essas máquinas trabalham em uma determinada faixa de frequência de vibrações para atingir a frequência de ressonância do pedúnculo do grão de café, promovendo a derriça (COELHO et al., 2015).

As colhedoras de café são projetadas com dois cilindros de varetas, os quais são responsáveis por promover a vibração dos galhos da planta de café durante a colheita, conforme esquema apresentado na Figura 1. Geralmente, estes cilindros são produzidos a partir de um tubo sem costura, cuja especificação é aço SAE 1010 a SAE 1030 com 0,5\% de molibdênio (Mo) e 0,5\% de cromo (Cr). Estes cilindros de varetas geralmente possuem espessura de parede de 9 mm e diâmetro externo de 150 mm (CAMINAGA; BUTTON, 2013). Para realizar a função de derriça dos grãos de café, o cilindro de varetas trabalha em modo de vibração. A frequência de vibração possui faixa de regulagem, que é compreendida pela força de desprendimento do grão de café, os quais variam entre 7,54 N a 11,81 N para a condição de maturação de café tipo verde até cereja e, entre 5,44 N a 7,21 N, para a condição de maturação de café tipo Catuaí vermelho (COELHO et al., 2015). 




Figura 1- Dois cilindros de varetas de nylon, responsáveis por realizar a colheita

Nos dois cilindros de varetas da colhedora, são soldados pequenos tubos que servem de suporte para receber as varetas de nylon, os quais são responsáveis por promover a derriça dos grãos de café por meio de vibrações mecânicas. Na extremidade superior ou inferior do cilindro de vareta, dependendo do modelo da colhedora de café, são soldados eixos de aço maciço com especificação SAE 1045 para acoplamento de mancais. A soldagem entre o cilindro e dois flanges ocorre pelo processo soldagem a arco elétrico sob proteção gasosa ativa com alimentação de arame consumível (MAG), conforme NBR 13043 (ABNT, 1993), também denominado por Gas-Shielded Metal Arc Welding (GMAW), sendo um flange com diâmetro de $260 \mathrm{~mm}$ e espessura de $26 \mathrm{~mm}$ e outro com um diâmetro de $360 \mathrm{~mm}$ e espessura $35 \mathrm{~mm}$, equidistantes de 150 mm (MACABÚ; SANTOS; LIMA, 2014).

As indústrias em geral têm apresentado preocupação com respeito à qualidade da solda empregada em seus equipamentos. A escolha correta do processo e do procedimento de soldagem visa garantir êxito e qualidade do produto final. A soldagem realizada conforme normas AWS (American Welding Society) garante a resistência mecânica do equipamento e especifica os testes que devem ser realizados para determinar as propriedades mecânicas da junta soldada para cada tipo de solda (ARIAS; BRACARENSE, 2015).

Máquinas agrícolas derriçadoras normalmente trabalham com frequências próximas à ressonância do material orgânico de derriça. Considerando vibrações aliadas a imperfeições em regiões soldadas na estrutura destas máquinas podem originar fraturas em componentes ou sistema mecânico (FERREIRA JUNIOR et al., 2016; SILVA et al., 2018; SOUZA et al., 2018).

Diante disso, este trabalho tem como objetivo realizar uma investigação na fratura ocorrida entre a solda de um cilindro vibrador de varetas de uma colhedora de café e seu flange. Para isso, foram realizados ensaios de análise química por espectrometria óptica do material do cilindro e flange, além de ensaios de tração em corpos de prova extraídos da peça fraturada, 
ensaios de dureza Brinell para averiguar a resistência à penetração, com a finalidade de validar os resultados da análise química, para averiguar as propriedades mecânicas do aço que constitui o cilindro vibrador de varetas. Além disso, ensaios de dureza Brinell e Vickers foram realizados para avaliar a região soldada, sendo recomendados para análise de dureza pós-soldagem (CHIAVERINI, 1986). Realizaram-se ainda a análise de características microestruturais por microscópio eletrônico de varredura (MEV) para revelar a solda e indicar a zona termicamente afetada, defeitos provenientes do processo de soldagem e características de fatura dúctil e frágil. A partir dos resultados encontrados, foi realizado um diagnóstico de falha, como em Magalhães, Fontes e Melo (2012).

Todos os ensaios foram realizados no intuito de prover informações relevantes sobre o material analisado e investigar o motivo da falha e, consequentemente, propor correções no processo de fabricação do cilindro de varetas, a fim de não danificar a máquina e comprometer a colheita, evitando-se manutenções periódicas.

\section{MATERIAL E MÉTODOS}

Este trabalho foi iniciado após a ocorrência de uma fratura em campo no cilindro de varetas de uma colhedora de café, depois de três anos de atividade em uma lavoura do sul de Minas Gerais, nas proximidades da cidade de Elói Mendes, em que a empresa fabricante da máquina cedeu a peça fraturada para análise. A partir daí, iniciou-se diagnóstico da falha, buscando-se investigar a origem da fratura na base do cilindro de varetas, a qual se estendeu em forma espiral, conforme a Figura 2.



Figura 2 - Região fraturada do cilindro de vareta de uma colhedora de café

$\mathrm{Na}$ colhedora analisada, o sistema mecânico que promove a vibração do cilindro de varetas está localizado na região inferior da máquina. Este sistema está acoplado ao cilindro de 
varetas, que é produzido a partir de duas chapas de aço SAE 1020. As duas chapas têm dimensões de $750 \mathrm{~mm}$ de comprimento, $360 \mathrm{~mm}$ de largura e $15 \mathrm{~mm}$ de espessura. Essas chapas possuem furos de diâmetro de $55 \mathrm{~mm}$ no centro para realizar a fixação do eixo do cilindro de varetas. Equidistantes deste furo existem dois outros furos de mesmo diâmetro para alojamento dos dois contrapesos de $25 \mathrm{~kg}$ cada um. Nos quatro vértices das duas chapas são fixados 4 parafusos espaçadores com $30 \mathrm{~mm}$ de diâmetro cada. No interior das duas chapas foram alojados dois contrapesos que giram em função do cilindro de varetas com o auxílio de polias e correia dentada, com a finalidade de realizar a vibração do sistema, conforme esquema apresentado na Figura 3.



Figura 3 - (a) Mecanismo de vibração e (b) esquema de contrapesos do cilindro de varetas

Há informação por parte do fornecedor da colhedora que o flange é soldado no cilindro utilizando o processo GMAW/MAG. A espessura da parede do cilindro de varetas é de $9 \mathrm{~mm}$ e do flange é de $35 \mathrm{~mm}$.

Notou-se que a fratura no cilindro de varetas iniciou-se na região soldada entre o flange inferior e o cilindro. Segundo Bannantine, Comer e Jamesl (1990), as amostras utilizadas para testes devem ser originadas de regiões de ocorrência da fratura. Assim, amostras do cilindro de varetas e flange foram mapeadas e, em seguida, retiradas corpos de prova (CPs), conforme a Figura 4. Foram confeccionados 7 CPs do flange e 7 CPs do cilindro vibrador de varetas para diagnóstico da falha, sendo retirados em posições denominadas por CP1, CP2 e CP3, em que $\mathrm{CP} 1$ e CP2 correspondem ao cilindro vibrador de varetas e CP3 à região soldada entre flange e cilindro vibrador de varetas, divididos da seguinte forma: 
- 2 CPs para análise química na posição CP1 e CP3;

- 1 CP para ensaio de dureza Brinell na posição CP1;

- $1 \mathrm{CP}$ para ensaios MEV da região de fratura na posição CP1;

- 3 CPs para ensaios de tração do cilindro de varetas na posição CP2;

- 3 CPs para ensaios metalográficos da junta soldada na posição CP3;

- 3 CPs para ensaios de revelação da solda nital $10 \%$ da junta soldada CP3;

- 3 CPs para ensaios de dureza Vickers na região da junta soldada CP3.



Figura 4- Retirada de CPs para análises (CP1) de fratura, (CP2) químicas e de tração, (CP3) da junta soldada

Após separação, as amostras foram preparadas para análise química no intuito de verificar as características do material do cilindro vibrador de varetas e do flange, que evidenciam as propriedades mecânicas do aço por meio das frações volumétricas das propriedades químicas (AMARAL et al., 2017). O ensaio de dureza Brinell foi usado para identificar as características de resistência à penetração do material do cilindro vibrador de varetas no intuito de comparar com os resultados da análise química do mesmo material.

Como procedimento de preparação do CP1 e CP3, retirou-se a região a ser analisada, a qual foi limada e polida (Figura 5 e 6), para realizar o ensaio de espectrometria de emissão ótica, utilizando o espectrômetro Spectromax, calibrado pelo fabricante, com confiabilidade de 95\%, realizando os ensaios a uma temperatura de $28^{\circ} \mathrm{C}$ utilizando as normas ASTM E 415:2017 (ASTM, 2017), ASTM E 1086:2014 (ASTM, 2014) e ASTM A 751:2014 (ASTM, 2014), segundo instruções técnicas IT Lab 249 revisão 09.

O ensaio de dureza Brinell no cilindro vibrador de varetas foi realizado a partir do emprego dos equipamentos durômetro universal dura vision DV30 e termo-higrômetro digital, ambos calibrados pelo laboratório Rede Brasileira de Calibração (RBC), a uma temperatura de 
$23,4{ }^{\circ} \mathrm{C}$, com penetrador de $2,5 \mathrm{~mm}$ de diâmetro e a aplicação de uma carga de 187,5 Kgf, utilizando três testes de penetração, segundo a norma NBR ISO 6506-1:2010 (ABNT, 2010).



Figura 5 - Preparação corpo de prova para análise química e dureza Brinell



Figura 6 - Corpo de prova para espectrometria de emissão ótica

Os CPs foram retirados para ensaios de tração por meio de um maçarico que trabalha com temperaturas elevadas (acima de $1400{ }^{\circ} \mathrm{C}$ para fusão do material). Por esse motivo, alguns cuidados foram tomados, principalmente, respeitando-se o aporte térmico do processo e elevação da dureza nas proximidades do corte. Foram considerados mais de $6 \mathrm{~mm}$ de sobre metal nos blanks, tanto no comprimento quanto na largura para fins usinagem final e consequente obtenção dos CPs (Figura 7). Vale ressaltar que os CPs para os ensaios de tração foram usinados conforme norma NBR ISO 6892-1:2013 (ABNT, 2013), com dimensões padrão, conforme especificações do tipo 1 (Figura 8). O procedimento para o ensaio de tração foi realizado à temperatura de $24,5^{\circ} \mathrm{C}$, utilizando uma máquina universal de ensaio. 




Figura 7 - Preparação dos blanks (A) e confecção dos CPs (B) para ensaio de tração

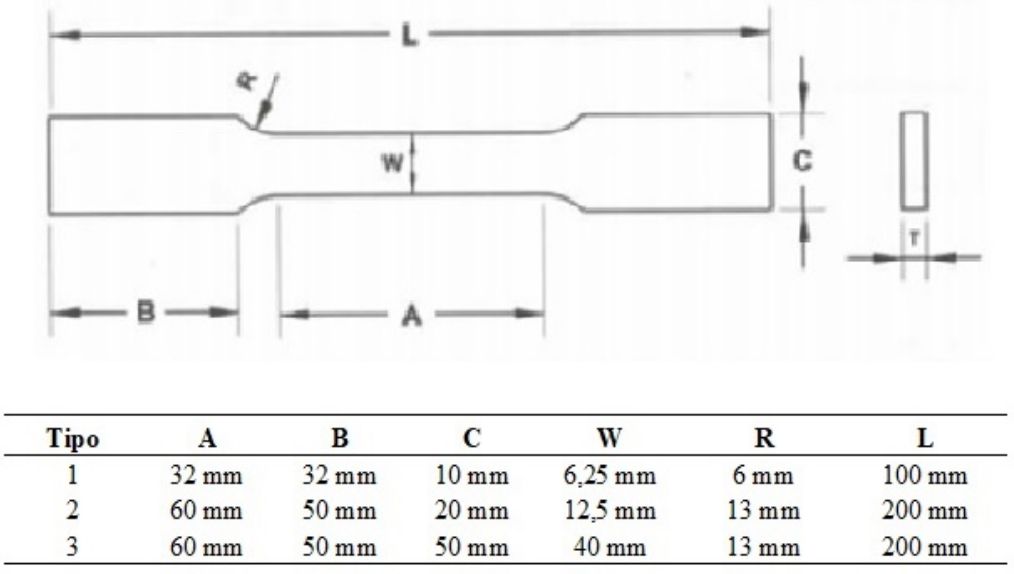

Figura 8 - Dimensões de CPs para o ensaio de tração conforme norma ASTM A370 (ASTM, 2012)

Utilizando parte da fratura extraída do CP1, procedeu-se a análise química e dureza Brinell do material com auxílio do MEV (modelo JEOL - JSM-6510LV) a partir da fixação da amostra em um suporte metálico e inserção no porta-amostra do microscópio, realizando a análise em duas regiões da amostra (Figura 9).



Figura 9 - Regiões de fratura submetidasà análise MEV

Por fim, analisou-se a região soldada (CP3), utilizando-se dois procedimentos, sendo a análise de dureza Vickers, para verificar a resistência mecânica a penetração e a metalografia 
com ataque de ácido nital 10\%, para revelar os cordões de solda, possíveis descontinuidades, zona fundida e aporte térmico (Figura 10).

O ensaio de dureza Vickers foi realizado para análise de pequenas regiões, utilizando um penetrador em formato de pirâmide com diâmetro de base quadrada em sete pontos da peça, por meio da aplicação de uma carga de $10 \mathrm{Kgf}$ a uma temperatura de $22,3{ }^{\circ} \mathrm{C}$, conforme norma NBR ISO 6507-1 (ABNT, 2010), a partir de Microdurômetro ótico Wolpert e Shimadzu.



Figura 10 - CP3 para os ensaios metalografia nital 10\% e dureza Vickers

\section{RESULTADOS E DISCUSSÃO}

Os resultados da análise química do material do cilindro e flange estão apresentados na Tabela 1.

Tabela 1 -Análise química dos materiais do cilindro e flange

\begin{tabular}{lcc}
\hline Elementos & $\begin{array}{c}\text { Concentração no } \\
\text { cilindro (\%) }\end{array}$ & $\begin{array}{c}\text { Concentração no } \\
\text { flange (\%) }\end{array}$ \\
\hline Carbono (C) & 0,2113 & 0,2066 \\
Manganês (Mn) & 0,8446 & 1,1518 \\
Silício (Si) & 0,1872 & 0,1737 \\
Fósforo (P) & 0,0162 & 0,0220 \\
Enxofre (S) & 0,0075 & 0,0072 \\
Cobre (Cu) & 0,0014 & 0,0047 \\
Cromo (Cr) & 0,0311 & 0,0188 \\
Níquel (Ni) & $\mathrm{ND}$ & $\mathrm{ND}$ \\
Molibdênio (Mo) & 0,0096 & 0,0063 \\
Vanádio (V) & 0,0009 & 0,0019 \\
Tungstênio (W) & $\mathrm{ND}$ & $\mathrm{ND}$ \\
Titânio (Ti) & 0,0020 & 0,0148 \\
\hline
\end{tabular}

Fonte: Autores (2018). 
Os resultados da análise química apresentam elementos que contribuem direta ou indiretamente para aumento da dureza do material, sendo que a quantidade destes elementos foi considerada baixa para os dois materiais analisados, em torno de $0,20 \% \mathrm{C}$, o que caracteriza aços com baixo teor de carbono. Os outros elementos importantes, como silício ( $\mathrm{Si}$ ), com 0,17 \% manganês (Mn), com 1,15 \%, são considerados desoxidantes. É importante salientar que o manganês (Mn) acima de 1,6 \% aumenta a resistência à abrasão do material. Os demais elementos, como o fósforo (P) e o enxofre (S), são considerados impurezas originados no início do processo de fabricação do material e podem comprometer o processo de soldagem. A presença de cobre $(\mathrm{Cu})$ no aço pode ser considerada benéfica para a redução de corrosão, com valores inferiores a $0,6 \%$. O cromo $(\mathrm{Cr})$, níquel $(\mathrm{Ni})$, vanádio $(\mathrm{V})$, molibdênio $(\mathrm{Mo})$, tungstênio (W), titânio (Ti) são considerados elementos presentes nos aços liga. Como estes elementos apresentam baixa concentração, pode ser desconsiderada a possibilidade de se tratar de um aço liga (SOEIRO JUNIOR; ROCHA; BRANDI, 2013).

Diante das análises químicas do flange e do cilindro de varetas, por se tratar de aço de baixo teor de carbono, deu-se atenção para o teor do carbono equivalente (CE) (MARQUES; MODENESI, 2014), conforme Equação 1.

$$
C E=C+\frac{M n}{6}+\frac{C r+M o+V}{5}+\frac{N i+C u}{15}
$$

O CE do material do flange foi de $0,40428 \%$ e do material do cilindro de varetas foi de $0,3607 \%$. Com isso, pode-se afirmar que o material do flange está no limite da boa soldabilidade. Neste sentido, o maior cuidado que deve ser tomado é no sentido de reduzir o aparecimento da microestrutura de martensita. Esta microestrutura é dura, consequentemente muito frágil, o que facilita o aparecimento de trincas na região da Zona Termicamente Afetada (ZTA) do material soldado (ALBUQUERQUE et al., 2011; MARQUES; MODENESI, 2014).

A utilização do procedimento de pré-aquecimento do material do flange pode favorecer a execução da soldagem, evitando-se trincas por hidrogênio, o que possibilita trabalhar com correntes e tensões baixas. Isso pode reduzir o aparecimento de mordeduras nas margens da solda. Outro fator a ser levado em consideração é a taxa de resfriamento, o que reduz o aparecimento de microestrutura indesejável como a martensita e proporciona o aparecimento da microestrutura bainita.

Os resultados de dureza Brinell (HB) comprovaram que o material do cilindro de varetas se trata de um aço de baixo teor de carbono, conforme a Tabela 2. 
Tabela 2 -Análise de dureza Brinell do material do cilindro de varetas

\begin{tabular}{lc}
\hline Ensaio & Resultados (HB) \\
\hline Valor 1 & 150,0 \\
Valor 2 & 149,0 \\
Valor 3 & 151,0 \\
Média & 150,0 \\
\hline
\end{tabular}

Fonte: Autores (2018).

No intuito de se verificar a influência da microestrutura resultante no material em função do processo da soldagem, foram realizados ensaios de dureza Vickers na região da solda nos três CPs onde ocorreu fusão, conforme a Figura 11.



Figura 11 - Pontos coletados nos ensaios de dureza Fonte: Autores (2018).

Os ensaios de dureza Vickers (HV) na região transversal da solda forneceram valores (Tabela 3) que não evidenciaram a homogeneidade do metal depositado, apenas comprovam dureza menor no metal base, dureza maior na ZTA e dureza intermediária (no geral) no metal de adição. Os valores de dureza foram extraídos a partir de sete impressões no material, partindo do flange e percorrendo a ZTA até o metal base do cilindro de varetas. 
Tabela 3 -Resultados dos ensaios de dureza Vickers

\begin{tabular}{ccccccc|c}
\hline Pontos & $\begin{array}{c}\text { CP1A } \\
\text { (HV) }\end{array}$ & $\begin{array}{c}\text { CP1B } \\
\text { (HV) }\end{array}$ & $\begin{array}{c}\text { CP2A } \\
\text { (HV) }\end{array}$ & $\begin{array}{c}\text { CP2B } \\
(\text { HV) }\end{array}$ & $\begin{array}{c}\text { CP3A } \\
\text { (HV) }\end{array}$ & $\begin{array}{c}\text { CP3B } \\
\text { (HV) }\end{array}$ & $\begin{array}{c}\text { Desvio } \\
\text { padrão } \\
\text { Linear }\end{array}$ \\
\hline 1 & 154,7 & 154,7 & 161,7 & 155,0 & 159,1 & 170,1 & 5.52 \\
2 & 216,5 & 216,5 & 210,0 & 200,1 & 215,4 & 220,3 & 6.57 \\
3 & 208,3 & 208,3 & 213,2 & 209,3 & 211,8 & 212,5 & 2,00 \\
4 & 202,5 & 202,5 & 203,8 & 192,5 & 204,1 & 206,9 & 4,52 \\
5 & 198,8 & 198,8 & 200,5 & 178,7 & 197,2 & 197,2 & 7,46 \\
6 & 177,0 & 177,0 & 179,2 & 187,0 & 190,6 & 193,1 & 6,54 \\
7 & 153,0 & 153,0 & 151,5 & 148,2 & 166,8 & 242,3 & 33,24 \\
\hline Desvio padrão CP & 23,91 & 23,91 & 22,75 & 21,01 & 20,12 & 21,04 & \\
\hline
\end{tabular}

Fonte: Autores (2018).

Quando comparado com os resultados de Silva e Bracarense (2003), Figura 12, em que a média dos valores de resistência mecânica e escoamento, foram 49,50 kgf/mm e 35,9 $\mathrm{kgf} / \mathrm{mm} 2$, respectivamente, nota-se que o limite de resistência a tração média obtido neste trabalho foi de $53,03 \mathrm{kgf} / \mathrm{mm}^{2}$ e o escoamento ocorreu em uma média de $35.1 \mathrm{kgf} / \mathrm{mm}^{2}$ (Tabela 4), ou seja, valores próximos, exceto para o alongamento.



Figura 12 - Tensão por deformação (SILVA; BRACARENSE, 2003). 
Tabela 4 - Ensaio de tração do material do cilindro

\begin{tabular}{llccc}
\hline Ensaio & un. & CP1 & CP2 & CP3 \\
\hline Resistência à tração (Rm) & $\mathrm{Kgf} / \mathrm{mm} 2$ & 52,4 & 53,4 & 53,3 \\
Resistência ao Escoamento Superior & $\mathrm{Kgf} / \mathrm{mm} 2$ & 35,7 & 35,1 & 34,5 \\
Alongamento Percentual Após Ruptura & $\%$ & 40,0 & 41,0 & 41,5 \\
Largura & $\mathrm{mm}$ & 6,32 & 6,32 & 6,32 \\
Espessura & $\mathrm{mm}$ & 8,25 & 8,25 & 8,25 \\
Força Máxima (Fm) & $\mathrm{kgf}$ & 2734 & 2784 & 2778 \\
\hline
\end{tabular}

Fonte: Autores (2018).

Outro fator importante, que deve ser levado em consideração, é o surgimento das trincas induzidas pela presença de hidrogênio. Consumíveis mal armazenados, sujeiras, graxas, óleo, poeira e umidade são fontes de hidrogênio que pode penetrar no material na solda e se dissociar em austenita após 48 horas, podendo surgir trincas na ZTA ou no cordão de solda (ALBUQUERQUE et al., 2011; MARQUES; MODENESI, 2014). Nesse caso, a utilização do MEV pode facilitar a observação e análise de como as trincas evoluíram no material na região soldada.

Uma parte da região fraturada do cilindro foi utilizada para ensaios MEV para avaliação da fratura. Esta investigação direcionou alguns pontos importantes em relação ao estudo de caso. Para isso, foi realizada uma varredura em duas regiões dos CPs, onde foi possível observar fratura dúctil (Figuras 13B e 13C), uma vez que não foi observado aparecimento de clivagem. Já na segunda região fraturada, observou-se fratura frágil, devido à presença de clivagem (Figuras 13E e 13F,) além de trincas nos contornos de grãos (Figura $13 \mathrm{~F})$.



Figura 13 - Primeira região fraturada da amostra com aumento de 9x(A), 150x(B) e 1000x(C); segunda região fraturada em $\mathrm{MEV}(\mathrm{D})$ com aumento de $1600 x(\mathrm{E})$ e $1400 x(\mathrm{~F})$ Fonte: Autores (2018). 
A partir dos ensaios no MEV, também foi possível observar microtrincas (retângulos em vermelho nas Figuras 14A, B, C, D e F) e inclusões nas extremidades do material do cilindro de varetas, circuladas em amarelo na

Figura 14.



Figura 14 - Regiões de fratura no material do cilindro de varetas (A, B, C, D, e F) e inclusões no material, com aumento de 1000 vezes (A, B, e E)

Fonte: Autores (2018).

Pode-se notar ainda a presença de microestruturas de ferrita nas amostras (parte clara da Figura 15) e perlita (parte escura da Figura 15), além de deformação plástica nas extremidades dos CPs. A partir das imagens coletadas via MEV notou-se que, diante da composição química das amostras e o processo de fabricação do material, esta estrutura era esperada.



Figura 15 - Presença de microestruturas de ferrita e perlita com aumento de 100x(A) e com aumento de 200x (B, C e D)

Fonte: Autores (2018).

O resultado da metalografia da solda com ataque de ácido nital 10\% está apresentado na Figura 16. 




Figura 16 - Ataque com ácido nital 10\% para revelação da solda Fonte: Autores (2018).

Além da falta de fusão, outros defeitos na solda foram observados, como trinca e porosidade. Considerando que foi encontrada, na raiz da solda, falta de fusão e que isto pode ser indício de sujeiras na poça de soldagem, deve-se levar em conta o efeito da formação de trinca por hidrogênio. Observam-se estes defeitos de soldagem, com maior nitidez, com o auxílio da Figura 17.
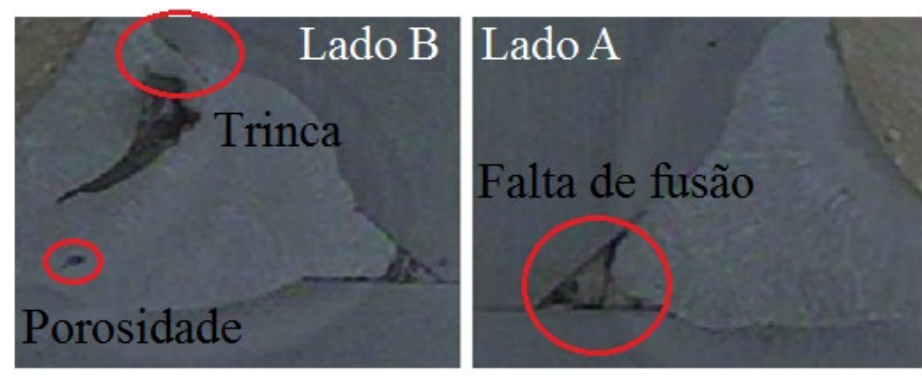

Figura 17 - Detalhe da falta de fusão, trinca e porosidade Fonte: Autores (2018).

Os resultados metalográficos da junta soldada confirmaram uma quantidade considerável de pequenos defeitos, que somados, se tornam ameaças reais para a propagação de trincas. Podendo, ainda, estar relacionadas com outros problemas de soldagem, como a porosidades, falta de fusão e trincas. Problemas de soldagem da mesma natureza, como descontinuidades (porosidade) e trincas, também foram encontrados por Arias e Bracarense (2015), que avaliaram propagação de trinca por fadiga, porém em situações de soldas subaquáticas por meio de avaliação fora da água.

Notou-se ainda que, na região onde o sistema mecânico promove a vibração, foi realizada a usinagem no interior do cilindro de varetas até nas proximidades do centro do flange, reduzindo a espessura da parede menor para $8,0 \mathrm{~mm}$. Uma seção transversal do cilindro é 
apresentada na Figura 18, evidenciando o quanto avançou a usinagem do cilindro de varetas na parte interna, o que pode ser indício de concentração de tensão na peça.


Figura 18 - Detalhe da região usinada do cilindro de varetas na parte interna Fonte: Autores (2018).

Após análise dos corpos de prova dos materiais e os resultados obtidos, os problemas encontrados na soldagem direcionam a uma proposta de melhoria do processo, trazendo como resultados alguns métodos que auxiliam no procedimento até então usado. São eles:

- Adicionar ao processo o aquecimento do flange para evitar o trabalho em altas tensões e correntes, evitando o aparecimento de descontinuidade no cordão de solda, além de eliminar mordeduras no material do cilindro vibrador de varetas, evitando assim possível início de trinca.

- Alterar chanfro duplo meio v para duplo j com a finalidade de evitar falta de fusão na raiz da solda.

- Incluir o processo de limpeza esmerilhado no início da soldagem, para eliminar impurezas que podem ocasionar inclusões e possíveis contaminações de hidrogênio para o metal fundido.

- Fixar em três passes o procedimento, com a finalidade de padronizar e reduzir o aporte térmico na ZTA.

- O monitoramento de temperatura entre os passes pode ser útil para reduzir contração desnecessária e reduz a dissociação do hidrogênio na austenita.

- Pós aquecimento para reduzir a formação de microestruturas indesejadas e fornecer alivio de tensão para região soldada.

O resumo das características da soldagem pode ser observada no Quadro 1 de especificações de soldagem (EPS). 


\begin{tabular}{|c|c|c|c|c|c|}
\hline \multicolumn{6}{|c|}{ EPS-Especificação do Processo de Soldagem } \\
\hline \multicolumn{6}{|c|}{ Detalhe da Junta } \\
\hline \multicolumn{6}{|c|}{ Descrição: Junta em formato duplo J } \\
\hline \multicolumn{4}{|c|}{ Metal Base: ER70S6 } & \multicolumn{2}{|c|}{ Posição: Plana2G Chanfro e $2 \mathrm{~F}$ fora } \\
\hline \multicolumn{4}{|c|}{ Pré-aquecimento } & \multicolumn{2}{|c|}{ Tratamento Térmico após soldagem } \\
\hline \multicolumn{4}{|c|}{$\begin{array}{l}\text { Temperatura de Preaquecimento (Mín.): } 100{ }^{\circ} \mathrm{C} \\
\text { Temperatura de Interpasse (Máx.): } 120{ }^{\circ} \mathrm{C} \\
\text { Manutenção do Preaquecimento: } 100 \text { a } 120{ }^{\circ} \mathrm{C}\end{array}$} & \multicolumn{2}{|c|}{$\begin{array}{l}\text { pós- aquecimento na faixa de } 200 \text { a } \\
300{ }^{\circ} \mathrm{C}\end{array}$} \\
\hline \multicolumn{4}{|c|}{ Características elétricas } & \multicolumn{2}{|l|}{ Técnica } \\
\hline \multicolumn{4}{|c|}{$\begin{array}{l}\text { Corrente: DC: (Faixa) } 23 \text { a } 24 \mathrm{~V} . \\
\text { Corrente (faixa): } 115 \text { a 120A } \\
\text { Tipo de transferência globular }\end{array}$} & \multicolumn{2}{|c|}{$\begin{array}{l}\text { Cordão Oscilante, } \\
\text { Limpeza inicial (esmerilhamento) } \\
\text { e interpasse (escovamento aço.) }\end{array}$} \\
\hline \multirow[t]{2}{*}{ Passe } & \multirow[t]{2}{*}{ Camada } & \multirow[t]{2}{*}{ Processo } & Metal de Adiçâ & & \multirow{5}{*}{$\begin{array}{l}\text { monitoramento entre os } \\
\text { passes, com a } \\
\text { temperatura ente } 100 \mathrm{a} \\
\qquad 120^{\circ} \mathrm{C}\end{array}$} \\
\hline & & & Especificação/Classificação & Diâmetro & \\
\hline Raiz & 1 & ER & ER70S6 & $1.2 \mathrm{~mm}$ & \\
\hline Enchimento & 2 & ER & ER70S6 & $1.2 \mathrm{~mm}$ & \\
\hline Acabamentos & 3 & ER & ER70S6 & $1.2 \mathrm{~mm}$ & \\
\hline
\end{tabular}

Quadro 1 - EPS para o processo de soldagem para a fabricação do cilindro vibrador de varetas da colhedora

\section{CONCLUSÕES}

A partir dos resultados encontrados em análise química dos materiais analisados, do ensaio de tração, MEV, dureza e metalografia da solda, conclui-se que:

- Os materiais do cilindro vibrador de varetas e flange são provenientes de aços com baixo teor de carbono equivalente, apresentando valores em torno de $0,36 \% \mathrm{C}$ no cilindro e $0,40 \% \mathrm{C}$ no flange.

- Os resultados dos testes de dureza Brinell serviram para confirmar o material constituinte do cilindro vibrador de varetas e o baixo teor de carbono. 
- O ensaio de tração apresentou valores de limites de resistência, escoamento e alongamento do material, bem como as características mecânicas do tubo, sendo comparado com valores da literatura, que apresentou resultados similares, exceto para o alongamento.

- Em relação ao processo de soldagem, realizou-se revelação em ácido nital $10 \%$, obtendo-se uma área de zona térmica afetada e passes de solda não uniformes, entre dois e três passes. Além disso, foram reveladas regiões de descontinuidade, falta de fusão, trincas e porosidade.

- Ensaios de dureza Vickers demostraram que, para um mesmo ponto analisado em diferentes amostras, não houve comportamento uniforme, mas em pontos da mesma peça o comportamento foi homogêneo, o que pode inferir em defeito no material do cilindro vibrador de varetas.

- Baseado na vibração da máquina para promover a colheita e o processo de fabricação da peça, devido à defeitos internos no material do cilindro vibrador de varetas, na soldagem, combinado com a vibrações cíclicas, pode-se diagnosticar que a fratura ocorreu por falhas no processo de fabricação do conjunto, principalmente na região da solda entre o cilindro vibrador de varetas e seu flange.

No intuito de se evitar defeitos provenientes do processo de soldagem do cilindro vibrador de varetas, sugeriu-se um EPS, levando-se em consideração um pré-aquecimento na faixa de $130^{\circ} \mathrm{C}$, limpeza antes da realização da soldagem, monitoramento entre passes, com a temperatura ente 100 a $120{ }^{\circ} \mathrm{C}$, pós-aquecimento na faixa de 200 a $300{ }^{\circ} \mathrm{C}$, seguido de um resfriamento controlado, em forno ou coberto com manta térmica de refratário, o que tende a reduzir a probabilidade de trincas na região de solda, no intuito de aumentar a vida útil da colhedora analisada.

\section{REFERÊNCIAS}

ABNT - ASSOCIAÇÃO BRASILEIRA DE NORMAS TÉCNICAS. NBR ISO 6506-1:2010. Materiais metálicos: ensaio de dureza Brinell - Parte 1: método de ensaio. 2010.

ABNT - ASSOCIAÇÃO BRASILEIRA DE NORMAS TÉCNICAS. NBR ISO 6507-1:2010. Materiais metálicos: ensaio de dureza Vickers - Parte 1: método de Ensaio, 2010. 
ABNT ASSOCIAÇÃO BRASILEIRA DE NORMAS TÉCNICAS. ABNT NBR ISO 6892-1: Materiais metálicos: ensaio de tração Parte 1: métodos de ensaio à temperatura ambiente. 2013.

ABNT - ASSOSIAÇÃO BRASILEIRA DE NORMAS TÉCNICAS. ABNT NBR 13043. Soldagem: números e nomes de processos - padronização. Rio de Janeiro: ABNT, 1993.

ALBUQUERQUE, S. F. et al. Evaluation of microstructure and mechanical proprerties of weld metals obtained by manual and automated welding process used in the welding of API 5L X80 Steel. Soldagem \& Inspeção, São Paulo, v. 16, n. 4, out./dez. 2011.

AMARAL, T. S.; CARBONI, M. C.; SCOTTI, A. Application assessment of a welding atlas of a niobium microalloyed bainitic steel. Soldagem \& Inspeção, São Paulo, v. 22, n. 2, p.163-173, jun. 2017.

ASTM A370. Standard Test Methods and Definition for Mechanical Testing of Steel Products. American Society for Testing and Materials, U.S.A, 2012.

ASTM E415. Standard Test Method for Analysis of Carbon and Low-Alloy Steel by Spark Atomic Emission Spectrometry. U.S.A, 2017.

ASTM E1086. Standard Test Method for Optical Emission Vacuum Spectrometric Analysis of Stainless Steel by the Point-to-Plane Excitation Technique, ASTM International, West Conshohocken, U.S.A, 2014.

ASTM A751, Standard test methods, practices, and terminology for chemical analysis of steel products , U.S.A, 2014.

ARIAS, A. R.; BRACARENSE, A. Q. Velocidade de propagação de trinca por fadiga de soldas subaquática molhadas: avaliação fora da água. Soldagem \& Inspeção, São Paulo, v. 20, n. 4, p. 403-411, dez. 2015.

BANNANTINE, J.; COMER, J.; H, JAMESL. Fundamentals of metal fatigue analysis. University of Illinois. Englewood Cliffs, NJ, Prentice Hall, 1990, 286 p.

CAMINAGA, C.; BUTTON, S. T. Mechanical properties of ausforged 27 MnSiVS6 microalloyed steel. Rem: Revista Escola de Minas, Ouro Preto, v. 66, n. 3, p. 331-338, jul. 2013.

CHIAVERINI, V. Tecnologia mecânica: materiais de construção mecânica. 2. ed. São Paulo: Makron Books, 1986.

COELHO, A. L. F. et al. Determinação das propriedades geométricas, físicas e mecânicas do sistema fruto-pedúnculo-ramo do cafeeiro. Revista Brasileira de Engenharia Agrícola e Ambiental, Campina Grande, v. 19, n. 3, p. 286-292, mar. 2015.

FERREIRA JUNIOR, L. G. et al. Recomendação para colheita mecânica do café baseado no comportamento de vibração das hastes derriçadoras. Ciência Rural, Santa Maria, v. 46, n. 2, p. 273-278, out. 2016. 
SOEIRO JUNIOR, J. C. S.; ROCHA, D. B.; BRANDI, S. D. Uma breve revisão histórica do desenvolvimento da soldagem dos aços API para tubulações. Soldagem \& Inspeção, São Paulo, v. 18, n. 2, p. 176-195, abr./jun. 2013.

MACABÚ, L. P.; SANTOS, S. H. C.; LIMA, S. S. Comparative analysis of solutions in shallow foundations or in pile foundations for an industrial machine. IBRACON de Estruturas e Materiais, v. 7, n. 2, p. 208-227, abr. 2014.

MAGALHÃES, R. R.; FONTES, C. H. O.; MELO, S. A. B. V. Failure analysis and design of a front bumper using finite element method along with durability and rig tests. International Journal of Vehicle Design, v. 60, n. 1/2, set. 2012.

MARQUES, P. V.; MODENESI, P. J. Algumas equações úteis em soldagem. Soldagem \& Inspeção, São Paulo, v. 19, n. 1, p. 91-102, jan./mar. 2014.

SILVA, E. P. et al. Structural static and modal frequency simulations in a coffee harvester's chassis. Revista Brasileira de Engenharia Agrícola e Ambiental, v. 22, n. 7, p. 511-515, jul. 2018.

SILVA, C. A.; BRACARENSE, A. Q. Procedimento de soldagem para recuperação de equipamentos de aço carbono exposto a grande quantidade de hidrogênio. In: CONGRESSO BRASILEIRO DE ENGENHARIA DE FABRICAÇÃO, mai. 2003.

SOUZA, V. H. S. et al. Evaluation of the interaction between a harvester rod and a coffee branch based on finite element analysis. Computers and Electronics in Agriculture, v. 150, p.476-483, jul. 2018.

\section{DADOS DOS AUTORES}

Nome: Carlos Ademir da Silva

E-mail: carlosademir2016@yahoo.com.br

Curriculum Lattes: http://lattes.cnpq.br/0289472289990238

Doutor em Engenharia Agrícola pela Universidade Federal de Lavras e Mestre em Engenharia Mecânica pela Universidade Federal de Minas Gerais; bacharel em Engenharia Mecânica pela Faculdade de Engenharia de Varginha. Atuou como assistente de Tecnologia, instrutor de formação profissional no SENAI e supervisor de soldagem na empresa Usiminas Mecânica. Atualmente é docente no Curso Técnico de Mecatrônica no CEFET/MG - Campus Nepomuceno.

Nome: Alexandre Assis Rezende Campos

E-mail: alexrezendeufv@gmail.com

Curriculum Lattes: http://lattes.cnpq.br/6951054613493121

Mestre em Engenharia de Sistemas e Automação pela Universidade Federal de Lavras na área de simulação numérica por elementos finitos, e graduação em Engenharia Mecânica pela Universidade Federal de Viçosa, atuando principalmente no seguinte tema: modelagem, suspensão passiva, matlab, vibração. 
Nome: Ricardo Rodrigues Magalhães

E-mail: ricardorm@deg.ufla.br

Curriculum Lattes: http://lattes.cnpq.br/9749306003740161

Doutor em Engenharia Industrial pela Universidade Federal da Bahia; bacharel em Engenharia Industrial Mecânica pelo Centro Federal de Educação Tecnológica de Minas Gerais, mestre em Mecatrônica pela Universidade Federal da Bahia. Atualmente é professor associado da Universidade Federal de Lavras. Tem experiência na área de Engenharia de Produção, com ênfase em Desenvolvimento de Produto, atuando principalmente nos seguintes temas: Método dos elementos finitos, análise de tensões e biomecânica.

Nome: Ednilton Tavares de Andrade

E-mail: ednilton@deg.ufla.br

Curriculum Lattes: http://lattes.cnpq.br/3989952107793554

Doutor e mestre em Engenharia Agrícola pela Universidade Federal de Viçosa; especialista em Engenharia de Segurança do Trabalho pela Universidade Federal Fluminense; bacharel em Engenharia Agrícola pela Universidade Federal de Lavras. Atualmente é professor Titular no Departamento de Engenharia Agrícola da Universidade Federal de Lavras; coordenador do Programa de Pós-Graduação em Engenharia Agrícola da Universidade Federal de Lavras. Apresenta experiência na área de Engenharia de Processamento de Produtos Agrícolas, com ênfase em secagem, armazenagem, qualidade, energia e segurança do trabalho.

Nome: Carlos Eduardo Silva Volpato

E-mail: volpato@deg.ufla.br

Curriculum Lattes: http://lattes.cnpq.br/6490213730609493

Doutor em Engenharia Agrícola pela Universidade Estadual de Campinas; mestre em Ciência Florestal pela Universidade Federal de Viçosa; bacharel em Engenharia Florestal pela Universidade Federal de Lavras. Atualmente é professor titular e chefe do Departamento de Engenharia na Universidade Federal de Lavras. Tem experiência na área de Engenharia Agrícola e Florestal, com ênfase em Máquinas Agrícolas e Florestais, atuando nos temas de mecanização agrícola e florestal, colheita de milho e forragens, agricultura de precisão e avaliação de motores com biocombustíveis.

Nome: Leomar Santos Marques

E-mail: leomar.marques@engenharia.ufjf.br

Curriculum Lattes: http://lattes.cnpq.br/8956473306586114

Doutorando em Engenharia Agrícola na Universidade Federal de Lavras, mestre em Engenharia de Sistemas e Automação pela Universidade Federal de Juiz de Fora; bacharel em Engenharia Mecânica pela Universidade Federal de Juiz de Fora. Tem experiência na área de Engenharia Mecânica, com ênfase em Robótica, Fabricação, Manutenção e Projetos. 